\title{
Penggunaan Blok Peritonsil untuk Mengurangi Nyeri Pasca Operasi Tonsilektomi
}

Dedy Kurnia

\begin{abstract}
Abstrak
Tonsilektomi merupakan jenis operasi Telinga Hidung Tenggorokan (THT) yang paling sering dilakukan, terutama pada usia anak-anak. Tonsilektomi dapat menyebabkan daerah orofaring terpapar yang bisa mengakibatkan nyeri karena spasme otot orofaring dan iritasi serabut saraf aferen. Selain nyeri pasca operasi tonsilektomi, pada sebagian kasus juga bisa terjadi perdarahan sekunder sebagai akibat pelepasan mediator selama operasi dan nyeri berlangsung. Tujuan penulisan ini adalah memaparkan beragam teknik blok peritonsil yang biasa digunakan. Blok peritonsil diketahui mampu memblok rangsang nyeri ini hingga 24 jam pasca operasi. Hal ini tergantung dari teknik, jenis obat dan dosis yang diberikan. Hasil penelitian sebelumnya didapatkan kombinasi dari ketamin dengan anestesi lokal untuk blok peritonsil sebagai pilihan terbaik untuk mengurangi nyeri pasca operasi, mencegah terjadinya perdarahan sekunder, mengurangi waktu perawatan pasca operasi dan mempercepat kondisi tubuh kembali normal.
\end{abstract}

Kata kunci: blok peritonsil, tonsilektomi, nyeri pasca operasi

\begin{abstract}
Tonsillectomy is the most common type of Ear Nose Throat (ENT) surgery, especially at the age of the children. Tonsillectomy may cause the exposed oropharyngeal area, causing pain due to oropharyngeal muscle spasms and irritation of afferent nerve fibers. In addition to postoperative tonsillectomy post pain, in some cases secondary bleeding may occur as a result of mediator release during surgery and pain. The objective of this study was to explain several peritonsil block that usually used. Peritonsil block is known to block the excitement of this pain until 24 hours post operation. This depends on the technique, type of drug and the dose given. From the previous study, a combination of ketamine and local anesthesia for peritonsil block was used as the best option for reducing postoperative pain, preventing secondary bleeding, reducing maintenance time and accelerating the resumption of body condition to normal.
\end{abstract}

Keywords: peritonsiller block, tonsillectomy, post operative pain

Affiliasi penulis: Bagian Anestesi Fakultas Kedokteran Universitas Andalas Padang/ RSUP Dr. M. Djamil Padang.

Korespondensi: Dedy Kurnia, Email: dedy.kurnia86@gmail.com

\section{PENDAHULUAN}

Nyeri merupakan salah satu problem dalam dunia kedokteran karena bukan hanya berkaitan dengan kerusakan dari saraf dan jaringan, tetapi juga menyangkut kelainan pada beragam mediator atau neurotransmiter. Para ahli sepakat tentang pentingnya arti pengendalian nyeri pasca operasi yang adekuat. ${ }^{1}$ Nyeri menurut International Association of The Study of Pain didefinisikan sebagai pengalaman sensorial atau emonsional yang tidak menyenangkan akibat adanya kerusakan jaringan yang nyata dan berpotensi merusak. $^{2}$

Tonsilektomi sendiri merupakan prosedur operasi tersering yang dilakukan oleh dokter THT (Telinga Hidung Tenggorok) pada anak-anak. Operasi ini dapat menyebabkan nyeri, perdarahan dan udem pada bagian yang terluka, tenggorok merasa sakit, kesukaran sewaktu menelan, gangguan makan dan minum, mual dan muntah hingga jatuh pada keadaan dehidrasi. Hal ini dapat menurunkan kepuasan pasien terhadap dilakukannya operasi tonsilektomi. Hasil 
studi retrospektif sebelumnya mendapatkan insiden perdarahan sekunder pasca tonsilektomi mencapai $10,1 \%$, hal ini terutama akibat terjadinya pelepasan mediator saat nyeri. ${ }^{1}$

Nyeri post operasi tonsilektomi yang sering terjadi pada anak-anak sendiri merupakan hal yang sulit dicegah karena daerah orofaring dan fossa peritonsiller merupakan daerah sensitif nyeri. Keduanya dipersarafi oleh cabang nervus Trigeminal (N.III) dan nervus Glossofaringeus (N.IX) yang sangat peka terhadap rangsangan nyeri dan terhubung ke korteks somatik di serebral. ${ }^{3}$

Manajemen nyeri pasca operasi tonsilektomi merupakan perhatian khusus baik oleh dokter THT maupun oleh dokter anestesi. Tingginya insiden nyeri atau kegelisahan pasca operasi tonsilektomi meningkatkan resiko perdarahan sekuder pasca tonsilektomi yang dapat terjadi. Untuk mencegah nyeri pasca operasi tersebut, perlu dikenal mekanisme timbulnya nyeri pasca operasi, dampak negatif adanya nyeri, upaya untuk mengurangi nyeri pasca operasi dan memilih analgetik yang rasional untuk mengatasi nyeri pasca operasi tonsilektomi. ${ }^{3}$

Blok peritonsil sebagai bagian anestesi lokal diketahui mampu memblok rangsangan nyeri hingga 24 jam pasca tonsilektomi. Blok peritonsil bekerja dengan memblok saraf nosiseptif, sehingga dapat menghambat rasa nyeri. Selain itu juga dapat mencegah timbulnya perdarahan sekunder dan membantu mengurangi konsumsi analgetik golongan opioid ataupun NSAIDs (Non Steroid Anti Inflamation Drug's) pasca tonsilektomi. ${ }^{4}$ Analgetik pasca operasi tonsilektomi seperti opiod dapat menyebabkan efek samping sedasi, depresi refleks batuk, mual dan muntah, hingga henti nafas. Sedangkan NSAIDs memiliki risiko terjadinya perpanjangan waktu perdarahan atau gangguan sistem saluran cerna. ${ }^{5}$

Tinjauan pustaka ini berusaha memaparkan beragam teknik blok peritonsil yang biasa digunakan, termasuk penggunaan obat anestesi yang digunakan seperti ketamin dan obat anestesi lokal (lidokain, pehakain, buvipakain, rupivakain, meperidine), baik secara tunggal maupun kombinasi, serta korelasinya dengan nyeri dan hasil pasca operasi tonsilektomi yang ditimbulkan.

\section{PEMBAHASAN}

\section{Anatomi Tonsil Palatina}

Tonsil palatina atau amandel merupakan jaringan limfoepitelial yang berbentuk oval dan terletak di dalam fosa tonsilaris pada kedua sudut orofaring. Bersama tonsil faringeal (adenoid), tonsil lingual dan tonsil tubal, membentuk cincin Waldeyer. ${ }^{6,7}$

Permukaan tonsil palatina ditutupi epitel berlapis gepeng yang juga melapisi invaginasi atau kripti tonsila. Banyak limfanodulus terletak di bawah jaringan ikat dan tersebar sepanjang kriptus. Tonsil palatina bagian lateral dibungkus oleh kapsul jaringan ikat fibrosa yang menutupi $4 / 5$ bagian lateral tonsil palatina. Antara kapsul dan muskulus konstriktor faring superior di bawahnya dipisahkan oleh jaringan ikat longgar. Hal inilah yang menyebabkan jaringan tonsil dapat diangkat secara komplit dengan teknik diseksi. ${ }^{8}$

Tonsil palatina mendapatkan perdarahan dari cabang-cabang arteri karotis eksterna, yaitu arteri maksilaris eksterna (menjadi arteri tonsilaris dan arteri palatina asenden), arteri maksilaris interna (menjadi arteri palatina desenden), arteri lingualis (menjadi arteri lingualis dorsal) dan arteri faringeal asenden. Sedangkan aliran vena pada tonsil palatina melalui vena paratonsilaris dan keluar menembus kapsul dan membentuk pleksus venosus faringeus yang bermuara ke vena fasialis yang selanjutnya bermuara ke vena jugularis interna. ${ }^{7,8}$

Tonsil ini diinervasi oleh dua jenis nervus kranialis. Nervus glossofaringeus dengan serabut saraf sensoriknya dan nervus Trigeminal terdiri dari serabut saraf sensorik disertai dengan serabut saraf motoriknya. $^{6,7}$

\section{Operasi Tonsilektomi}

Tonsilektomi adalah suatu tindakan operasi untuk mengangkat semua jaringan tonsil palatina. ${ }^{9}$ Tonsilektomi merupakan teknik lini pertama untuk mengangkat tonsil palatina dan merupakan prosedur operasi yang paling sering dilakukan pada usia anakanak dan relatif sering pada usia dewasa. ${ }^{10}$

Tonsilektomi merupakan pelayanan one day care (operasi sehari) di banyak fasilitas kesehatan. Teknik operasi tonsilektomi standar yang masih diterima hingga saat ini adalah teknik Sluder, diseksi, 
menjadi teknik yang paling sering digunakan selain Sluder (modifikasi guillotine). Teknik diseksi meliput: memegang tonsil, membawanya ke garis tengah, insisi membran mukosa, mencari kapsul tonsil, mengangkat dasar tonsil dan mengangkat tonsil palatina dari fossa peritonsiller dengan manipulasi hati-hati. ${ }^{11}$

Tonsilektomi juga dapat dilakukan bila terjadi infeksi yang berulang atau kronik, gejala sumbatan nafas serta kecurigaan neoplasma. ${ }^{12}$

Tonsilektomi dapat menimbulkan morbiditas berupa timbulnya nyeri, perdarahan, mual dan muntah, asupan peroral yang tidak adekuat, dehidrasi, infeksi, hingga pneumonitis akibat aspirasi darah. Dimana nyeri tenggorok menjadi keluhan yang paling sering terjadi pada pasien, baik anak-anak maupun dewasa, terutama pada hari pertama pasca tonsilektomi. ${ }^{8}$

Selama operasi dalam pengaruh anestesi, impuls nyeri memasuki sistem saraf pusat membentuk suatu keadaan hipereksitabel. Pemerosesan impuls aferen diubah menghasilkan pengurangan nyeri dan respon normal pada tubuh. Nyeri pasca tonsilektomi terjadi akibat adanya kerusakan jaringan yang mengeluarkan mediator-mediator yang dapat merangsang ujung saraf nyeri. ${ }^{8}$ Nyeri merupakan hambatan yang paling signifikan dalam rehabilitasi pasien pasca tonsilektomi dan kondisi tersebut dapat mempengaruhi besarnya kebutuhan analgetik yang diberikan, durasi perawatan rawat inap, asupan per oral dan pengembalian hemostasis tubuh ke fungsi awal. $^{13}$

\section{Nyeri Pasca Operasi Tonsilektomi}

Nyeri pasca tonsilektomi muncul karena kerusakan mukosa dan serabut saraf trigeminal dan glosofaringeus atau vagus, inflamasi dan spame otot faringeus yang menyebabkan iskemia. Siklus nyeri berlanjut sampai otot telah diselubungi kembali oleh mukosa. ${ }^{11}$ Trauma yang bisa terjadi selama operasi tonsilektomi menyebabkan pelepasan beragam mediator seperti histamin, prostaglandin, bradikinin dan sitokin proinflamasi. Nyeri pasca tonsilektomi dapat terjadi karena meditor yang dikeluarkan selama operasi merangsang ujung saraf nyeri. Selain itu semakin berat perenggangan mukosa yang terjadi pasca operasi menyebabkan rasa nyeri yang timbul

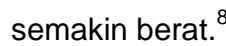

Spasme otot juga dapat menyebabkan nyeri pasca tonsilektomi, hal ini karena otot yang sedang berkontraksi menekan pembuluh darah intramuskuler dan menggurangi atau menghentikan sama sekali aliran darah. Kontraksi otot menyebabkan iskemia otot relatif sehingga timbul nyeri iskemia yang khas. Nyeri yang timbul akan menyebabakan respon reflektoris spame otot di daerah sekitar sumber nyeri. Spasme otot yang berkepanjangan akan mengganggu aliran darah setempat akibat jepitan terhadap pembuluh darah, sehingga terjadi iskemia dan hipoksia lokal. ${ }^{14}$

Iskemia menyebabkan kerusakan jaringan dan meningkatkan pelepasan mediator yang dapat membangkitkan impuls nyeri dan selanjutnya nyeri yang timbul akan membangkitkan spasme otot dan begitu seterusnya. ${ }^{14}$ Dimana berat ringannya nyeri pasca operasi tonsilektomi tergantung beberapa faktor, yaitu: kondisi kesehatan pasien, keterampilan operator, teknik tonsilektomi, komplikasi operasi dan managemen nyeri yang digunakan. ${ }^{11}$

\section{Manajemen Nyeri Pasca Operasi Tonsilektomi}

Nyeri pasca operasi tonsilektomi berbeda dengan nyeri yang terjadi di tempat lain, karena luka dibiarkan terbuka dan daerah luka berada di daerah yang aktif dan merupakan saluran untuk nutrisi. Manajemen nyeri pasca operasi tonsilektomi telah lama dianalisis, namun masalah nyeri pasca operasi tonsilektomi belum sepenuhnya terselesaikan. ${ }^{11}$

Terdapat beberapa upaya untuk mengurangi nyeri pasca operasi tonsilektomi tersebut termasuk memperbaiki penggunaan obat anestesi intra operatif, penggunaan kortikosteroid dan opioid atau NSAIDs, penyesuaian teknik pembedahan, hingga injeksi obat anestesi secara lokal intra operatif (blok peritonsil). ${ }^{15}$ Beragam upaya tersebut dilakukan untuk mencegah serabut sarah nosiseptif terangsang, maupun mencegah hantaran impuls di sepanjang saraf aferen ke medula spinalis dan melalui traktus anterolateral ke talamus kemudian menuju korteks somatosensorius, yaitu di gyrus cingularis dan insularis. ${ }^{14}$

Peranan blok peritonsil yang digunakan intra operatif yang diberikan sebagai tambahan terapi 
standar pada anestesi general untuk mengurangi nyeri pasca tonsilektomi masih kontroversial. ${ }^{14}$ Keuntungan blok peritonsil intra operatif antara lain: mengurangi nyeri pasca operasi, penurunan kehilangan darah dan perdarahan sekunder, serta mempermudah teknik diseksi yang dilakukan selama operasi. ${ }^{11}$ Beberapa studi klinis menunjukan blokade jalur sensoris dengan ketamin atau anestesi lokal sebelum dilakuknnya operasi dapat mencegah impuls nosiseptif mencapai medula spinalis sehingga dapat mengurangi nyeri pasca operasi. ${ }^{3}$

Cara kerja blok peritonsil dengan anestesi lokal sendiri secara molekuler berdasarkan ikatan reseptor spesifik. Dimana molekul obat anestesi lokal dapat mencegah konduksi saraf dengan cara berikatan dengan reseptor yang spesifik pada celah natrium. Seperti telah diketahui sebelumnya, bahwa untuk konduksi impuls saraf termasuk impuls nyeri pada nosiseptif dibutuhkan ion natrium untuk menghasilkan potensial aksi di saraf. ${ }^{11}$

\section{Teknik Blok Peritonsil}

Blok peritonsil pada tonsilektomi memerlukan perhatian besar, baik mengenai teknik, jenis obat anestesi, hingga dosis yang digunakan. Selain itu yang perlu diperhatikan dalam blok atau infiltrasi peritonsil adalah menghindari penyuntikan langsung ke pembuluh darah. Perlu dilakukan aspirasi sebelum melakukan penyuntikan, sehingga dapat mencegah timbulnya efek samping ke sistemik. ${ }^{13,16}$

Penyuntikan sebaiknya secara superfisial dan mengangkat jaringan submukosa dari pilar tonsilaris. Hal ini dilakukan untuk menghindari komplikasi serius pada jalan nafas. Perlu diperhatikan juga untuk tidak menyuntikan obat anestesi ke dalam substansi tonsil, hal ini dapat menghambat efek obat mencapai target area yang terletak di lateral dari kapsul tonsil (peritonsil). ${ }^{13,16}$

Pada penelitian yang dilakukan Brahmi dan Sutiyono (2015), dilakukan pemberian blok peritonsil pasca tonsilektomi pada anak-anak usia 6-8 tahun, yaitu sesaat sebelum pasien dibangunkan pasca anestesi umum. ${ }^{3}$ Blok peritonsil dilakukan pada fossa peritonsiller dengan menggunakan ketamin 0,2 $\mathrm{mg} / \mathrm{kgBB}$, diencerkan dengan 2 ampul pehakain, lalu disuntikkan $1 \mathrm{ml}$ posterior dan $1 \mathrm{ml}$ anterior fossa peritonsiller sebelum pasien diekstubasi. ${ }^{3}$ Pemberian ketamin dengan blok peritonsil terbukti mampu menurunkan nyeri pasca operasi tonsilektomi pada anak-anak dan juga menurunkan kebutuhan analgesia pasca operasi. ${ }^{17}$

Ketamin tidak hanya digunakan pada general anestesi, tetapi juga blok peritonsil post tonsilektomi. Blok reseptor norepinefrin dan serotonin merupakan kerja ketamin sebagai analgesia pada blok peritonsil. Aksi antinosiseptif dari ketamin melalui menghambat jalur monoaminergik nyeri. Ketamin juga saling berhubungan dengan reseptor kolinergik muskarinik dalam sistem saraf pusat, yang berpusat pada kerja agen antikolinesterase. Sedangkan pehakain yang digunakan merupakan kombinasi dari lidokain dan adrenalin. Pehakain sebagai pengencer ketamin digunakan untuk mempercepat onset kerja obat, dan efek hemostasis akibat efek vasokonstriktor hebat dan agregasi platelet dari adrenalin. ${ }^{3}$

Penelitian yang dilakukan Khademi et al (2011) juga membuktikan bahwa blok peritonsil dengan ketamin $0,5 \mathrm{mg} / \mathrm{kgBB}$ secara tunggal mampu menurunkan nyeri pasca operasi tonsilektomi dan menurunkan kebutuhan analgesik pasca operasi yang lebih efektif dibandingkan pemberian ketamin 0,5 $\mathrm{mg} / \mathrm{kgBB}$ secara intravena. ${ }^{18}$

Selama operasi, impuls nyeri masuk sistem saraf pusat dan menimbulkan keadaan hipereksitabel. Memblok impuls ini dengan obat analgesik sebelum operasi maupun infiltrasi anestesi lokal sebelum insisi merupakan variasi modalitas nyeri preemptif pada blok peritonsil. Penelitian Sonbaty et al (2011) memberikan blok peritonsil secara preemptif 3 menit sebelum dilakukannya tonsilektomi. ${ }^{4}$ Sonbaty et al menggunakan ketamin 0,5 $\mathrm{mg} / \mathrm{kgBB}$ dengan buvipakain $5 \mathrm{mg} / \mathrm{ml}$ atau tanpa buvipakain, dan dibandingkan dengan meperidin $1 \mathrm{mg} / \mathrm{kgBB}$ dengan buvipakain atau tanpa buvipakain. Hasil penelitian tersebut menunjukkan kombinasi ketamin dengan obat anestesi lokal (buvipakain) memberikan hasil penurunan nyeri pasca operatif yang lebih signifikan dibandingkan tanpa disertai pemberian obat anestesi lokal maupun hanya obat anestesi lokal saja (meperidin). ${ }^{4}$ 
Penelitian lain yang dilakukan Farmawy dan Rashad (2013) dengan ketamin 0,2 mg/kgBB secara tunggal sebagai blok peritonsil sebelum insisi juga mampu memberikan penurunan indeks nyeri yang lebih baik dan signifikan, baik dibandingkan ropivakain $0,2 \mathrm{mg} / \mathrm{kgBB}$ dan normal saline. ${ }^{19} \mathrm{Hal}$ ini menjadikan ketamin sebagai obat anestesi pilihan utama pada blok peritonsil, baik yang dipadukan dengan obat anestesi lokal maupun secara tunggal. ${ }^{19}$

Ketamin yang merupakan turunan dari phencyclidine bekerja di sejumlah lokasi target (reseptor) yang berbeda. Hal ini dapat menjelaskan efek analgesik ketamin yang terlepas dari rute administrasi. Ketamin merupakan antagonis pada reseptor $\mathrm{N}$ Methyl-D-Aspartate (NMDA) yang memiliki sifat stereo-selektivitas. Reseptor NMDA ditemukan di seluruh sistem saraf pusat dan memainkan peran penting dalam proses nosiseptif. Efek analgesik ketamin juga dapat diakibatkan oleh aktivitas agonis pada reseptor opioid dan interaksi dengan saluran natrium yang peka terhadap impuls nyeri. ${ }^{4}$

Naja et al (2005) yang melakukan pemberian blok peritonsil sebelum insisi pada tonsilektomi dengan anestesi lokal 1,5 $\mathrm{ml}$ tanpa disertai ketamin juga menunjukkan penurunan tingkat nyeri pasca operasi tonsilektomi dan waktu kembali ke aktivitas normal pada anak-anak, dibandingkan blok peritonsil dengan normal saline ataupun dengan anestesi general saja. ${ }^{20}$ Meskipun penurunan tingkat nyeri pasca operasi tonsilektomi secara signifikan hanya dapat ditemukan pada penggunaan blok peritonsil secara tunggal dengan jenis dan dosis obat anestesi lokal tertentu. ${ }^{4}$

Tidak hanya dapat dikombinasikan dengan obat anestesi lokal, ketamin pada blok peritonsil juga dapat dikombinasikan dengan tramadol. Kombinasi keduanya memberikan efek analgesia yang lebih cepat dan kuat, namun memberikan efek halusianasi pasca operasi dan efek Post Operatif Nausea and Vomiting (PONV). ${ }^{21}$ Kombinasi lain yang sering digunakan adalah Ketamin dan midazolam. Kombinasi obat ini efektif mencegah terjadinya PONV. Pemberian midazolam juga dapat mengurangi kerja kardiovaskuler dan peningkatan frekuensi denyut jantung yang disebabkan oleh penggunaan ketamin, meskipun demikian kombinasi keduanya justru memiliki efek analgesia yang singkat. ${ }^{3}$

Blok peritonsil tidak hanya mencegah timbulnya nyeri pasca operasi tonsilektomi yang bisa timbul hingga 7-10 hari pasca operasi, tetapi juga mampu mencegah timbulnya delayed hemorrhage yang umumnya terjadi pada $2 \%$ hingga $4 \%$ pasien. Umumnya pada pasien yang mendapatkan blok peritonsil memiliki durasi perawatan di Post Anesthesia Care Unit (PACU) dan waktu tinggal di RS yang lebih singkat. Dengan demikian blok peritonsil dapat meningkatkan kepuasan pasien terhadap operasi tonsilektomi yang diberikan. ${ }^{4}$

\section{PENUTUP}

Blok peritonsil dapat menjadi metode yang bisa digunakan untuk mengurangi nyeri pasca operasi tonsilektomi. Blok peritonsil dapat dilakukan setelah intubasi (sebelum insisi) ataupun sebelum ekstubasi (setelah tindakan selesai). Ketamin 0,2 atau 0,5 $\mathrm{mg} / \mathrm{kgBB}$ dapat menjadi pilihan utama sebagai obat anestesi yang diberikan. Dimana ketamin dapat secara tunggal atau dikombinasikan dengan obat anestesi lokal seperti pehakain atau bupivakain dan analgetik lain untuk mendapatkan hasil yang lebih baik dan efek samping yang lebih minimal.

\section{DAFTAR PUSTAKA}

1. Meriwijanti. Evaluasi efek analgesi pemakaian ketoprofen dan ketorolak intravena pasca tonsilektomi (tesis). Semarang: Program Pascasarjana Universitas Diponegoro; 2001.

2. Kumar $\mathrm{KH}$, Elavarasi P. Definition of pain and classification of pain disorders. J Adv Clin Res Insights. 2016;3:87-90.

3. Brahmi NH, Sutiyono D. Ketamin and peritonsiller infiltration as post operative tonsillectomi pain management in children. Jurnal Anestesiologi Indonesia. 2015; VII(2):114-9.

4. Sonbaty MI, Dahab MA, Mostafa A, Shanab OA. Preemptive peritonsillar ketamine infiltration: post operative analgesic efficacy versus meperidine. M.E.J. ANESTH. 2011;21(1):43-51. 
5. Choubsaz M, Mohseni G, Ahmadi SJ, Sadeghi M. Comparison of the effects of adding of ketamine to preincisional bupivacaine injection on post operative pain relief after tonsillectomy in children. Journal of Reports in Pharmaceutical Sciences 2017;6(1):68-76.

6. Adam GL, Boies LR, Higler PA. Boies buku ajar penyakit THT. Wijaya C, penterjemah. Edisi ke-6. Jakarta: EGC. 2013.hlm.337.

7. Wiatrak BJ, Woolley AL. Cummings otolaryngology head and neck surgery. Edisi ke-4. Philadelphia: Mosby. 2005.hlm.4135-65.

8. Farokah. Efektivitas Infiltrasi Lidokain Pada Peritonsil Untuk Mengurangi Nyeri Pasca Tonsilektomi (tesis). Semarang: Program Pascasarjana Universitas Diponegoro; 2012.

9. Grey RF. Synopsis of Otholaryngology. Edisi ke-5. Oxford Buttleworth Heinneman. 1992; p354-8.

10. Patrick N, Robert G. Dasar-dasar ilmu THT. Edisi ke-2. Jakarta: EGC; 2012.

11. Hermani B, Fachrudin D, Hutauruk SM, Riyanto BU, Susilo, Nazar HN. Tonsilektomi pada Anak dan Dewasa. Jakarta: Health Technology Assesment (HTA) Indonesia 2004; p1-25.

12. Rusmarjono, Arsyad SE. Nyeri tenggorok. Dalam: Buku ajar ilmu kesehatan telinga hidung tenggirik kepala \& leher. Edisi ke-7. Jakarta: Fakultas Universitas Andalas; 2016.

13. Nikandish R, Maghsodi B, Khademi S, Motazedim S, Kaboodkhani R. Peritonsillar infiltration with Buvipacaine and pethidine fer relief of post tonsillectomy pain: A randomised double-blind study. Anesthesia. 2008;63:20-5.
14. Guyton AC, Hall JE. Textbook of Medical Physiology. Edisi ke-12. Philadelphia: WB Sauders Company; 2015:583-92.

15. OhIms LA. Injection of local anesthetic in tonsillectomy. Arch Otolaryngol Head Neck Surg. 2001;127(10):1276-8.

16. Cook SP. Bupivacaine injection to control tonsillectomy pain. Arch Otolaryngol Head Neck Surg. 2001;127(10):1279.

17. Cho HK, Kim KW, Jeong YM, Lee HS, Lee JY, et al. Efficacy of ketamine in improving pain after tonsillectomy in children: meta analysis. PloS ONE 2014;9(6):e101259.

18. Khademi S, Ghaffarpasand F, Heiran HR, Yavari MJ, Motazedian S, Dehghankhalili M. Intravenous and pritonsiller infiltration of ketamin for post operatif pain after adeno-tonsillectomy: a randomized placebo controlled clinical trial. Med Princ Pract. 2011; 20:433-7.

19. Farmawy MS, Rashad MM. Preemptive analgesia by peritonsillar ketamine versus ropivacaine for post-tonsillectomy pain in children. Egypt $J$ Anaesth. 2014;30(1):1-5

20. Naja MZ, El-Rajab M, Kabalan W, Zlade MF, AlTannlr MA. Pre-incisional infiltration for pediatric tonsillectomy: a randomized double-blind clinical trial. Int J Pediatr Otorhinolaryngol 2005;69(10): 1333-41.

21. Ayatollahi V, Behdad S, Hatami M, Mostaghiun $H$, Baghianimoghadam B. Comparison of peritonsillar infiltration effect on Ketamin and Tramadol on Post Tonsillectomy pain: a double blinded randomized placebo controlled clinical trial. Croat Med J. 2012; 53(2):155-61. 